\title{
Preparation of High GABA-Enriched Yeast Extract by Non-Saccharomyces Yeasts Isolated from Korean Traditional Fermented Soybean Product
}

\author{
Nho-Eul Song, Da-Bin Lee, Seon-Hye Lee, and Sang-Ho Baik* \\ Department of Food Science and Human Nutrition, Jeonbuk National University, Jeonju 54896, Republic of Korea
}

Received: May 6, 2021 / Revised: June 27, 2021 / Accepted: June 29, 2021

High GABA-enriched yeast extract, for various nutritionally and pharmaceutically important functional foods, was prepared using a novel isolate of Debaryomyces hansenii JBCC541. Under optimized conditions, GABA conversion rates are significantly enhanced up to $7.55 \mathrm{~g} / \mathrm{l}$ by $D$. hansenii JBCC541, increasing their synthesis yield 40 times. The total amino acid content of the prepared yeast extract was $10733.86 \mathrm{mg} / \mathrm{l}$ (257.36 $\mathrm{mg} / \mathrm{g})$, consisting of alanine, lysine, glutamine, leucine, and valine as the primary amino acids. The GABA content was significantly enhanced up to $6790 \mathrm{mg} / \mathrm{l}(162.80 \mathrm{mg} / \mathrm{g})$ in the presence of glutamic acid, with approximately 10 -fold higher GABA production. Flavor amino acids were also highly enhanced, indicating that the prepared yeast extract might be useful for preparing various functional and sensuous foods. Our results were promising as a GABA-enriched yeast extract preparation tool ensuring a suitable food material level with the potential for functionally enhanced food industrial applications.

Keywords: Gamma-aminobutyric acid, Debaryomyces hansenii, yeast extract, amino acids, food additives

\section{Introduction}

$\gamma$-aminobutyric acid (GABA) is a non-protein amino acid that is distributed extensively in nature [1]. GABA is known as one of the major inhibitory neurotransmitters in the central nervous system of animals [2] and possesses many physiological functions such as a neurotransmitter, diuretic and tranquilizer effects, and induction of hypotension [3-5]. Due to various outstanding physiological functions of GABA, the needs extensively expanded in the area of pharmaceutical and functional foods industry. Although the GABA is usually found in natural products, but the GABA contents are commonly very low in natural foods and significantly differ depending on the origin [6]. Thus, the needs for a

\section{*Corresponding author}

Tel.: +82-63-270-3857, Fax: +82-63-270-3854

E-mail: baiksh@jbnu.ac.kr simple preparation on industrial scale or the preparation method for GABA enhanced foods are greatly increased [7, 8].

GABA is synthesized by glutamate decarboxylase (GAD) (EC 4.1.1.15), a pyridoxal 5'-phosphate dependent enzyme that catalyzes the irreversible $\alpha$-decarboxylation of L-glutamate to GABA [9], and is widely distributed among eukaryotes and prokaryotes [10]. Until now, the fungal strain Monascus purpureus has been shown to produce GABA [11]. Lactic acid bacteria (LAB) is the most investigated microorganism in production of GABA [12], and it was isolated to show GABA synthesis abilities from many fermented foods, including cheeses [9], paocai [13], fresh milk [14] and kimchi [15]. In the case of yeasts, Saccharomyces cerevisiae MJ2 strain which was isolated from the surface of kiwi was found to produce GABA [16]. Recently, the non-Saccharomyces yeasts such as Pichia amonala, $P$. jadinii, $P$. guilliermondii, and Candida utilis were being isolated from 
marine as GABA producing yeasts [17]. However, very few yeast strains which can produce GABA have been isolated and characterized from food sources to our current knowledge.

The Korean traditional fermented soybean product, meju, is a major ingredient used to prepare many fermented Korean soybean foods such as doenjang (soybean paste), ganjang (soy sauce), and gochujang (paper paste). Due to various microorganisms including bacteria, fungi, and yeasts are known to be distributed in meju, and would be a good source for indigenous functional strains and microbial enzyme catalysts due to the amino acid rich environments of meju. Specifically, the non-Saccharomyces yeasts such as Hansenular capsulata S-13 [18], C. versatilis, P. membranaefacieus [19], and Kluveromyces maxianus var. lactis [20] are currently found throughout the meju fermentation and showed functionality of the highest killer toxin activities, the 5'-ribonucleotides as flavor enhancers and galacto-oligosaccharide (GalOS), respectively.

Traditionally, yeast extract has been known as bacterial or cell culture media due to its high growth affective active compounds obtained by extracting the cell contents [21]. However, it has focused attention as food additives or bioflavouring materials in the food industry since it contains rich valuable amino acids and vitamin B complex as also nutritional active suppliers [22]. Moreover, a great attraction also are being increased recently due to its rich natural pool in nucleic acids, consisting of mainly ribonucleic acid after autolysis and partial hydrolysis of RNA, ribonucleotides such as guanosine 5'-monophosphate (GMP) and inosine 5'monophosphate (IMP), which substances are efficient flavour enhancers [23-25]. Two important chemical compounds responsible for flavour enhancement action in crude preparations of IMP and GMP are well known in the food industry and are now commercially available worldwide. The world market of flavour enhancers surpasses US $\$ 1.1$ billion per year [26].

This study was initiated to develop novel functional food additive material with high GABA content with yeast strains which contained various nutritive and bioflavour ingredient by adopting whole-cell reaction of novel non-Saccharomyces yeast [27-29]. Thus, we tried: 1) isolation of optimal indigenous yeast strains for whole-cell reaction from naturally fermented Korean traditional starter block, meju, 2) identification by chemical and molecular approaches and finally, 3) optimization of the whole-cell reaction by using the selected yeast starters for optimal synthesis of GABA and examined GABA contents with other valuable ingredients of the prepared yeast extract.

\section{Materials and Methods}

\section{Isolation of yeast-like strains}

The meju samples used in this study as microbial yeast sources were manufactured by using traditional methods in the Sunchang province (Korea). One gram of sample was suspended with $0.85 \%$ of sodium chloride solution, and then decimally diluted and homogenized. The $100 \mu$ of diluted samples were respectively inoculated on to the YM plate containing $25 \mathrm{unit} / \mathrm{ml}$ of Penicillin-streptomycin solution (Sigma, USA) and incubated at $29^{\circ} \mathrm{C}$ for $24-48 \mathrm{~h}$. The yeast-like isolates were cultured in the YM broth (Difco, USA) and also purified by successive streaking on YM agar to isolate single strains for further experiments.

\section{Screening of GABA producing yeast by whole-cell reaction}

To screen the high GABA producing yeast, a wholecell reaction (WCR) was carried out [17]. In brief, each isolates were grown at $10 \mathrm{~mL}$ of YM broth at $29^{\circ} \mathrm{C}$ for 24-48 h, and separated from broth by centrifugation at $8,000 \times g$ for $10 \mathrm{~min}$ at $4^{\circ} \mathrm{C}$. After washing with distilled water for two times, the cells ( $20 \%$, wet weight) were mixed with reactive solutions comprised of $10 \mathrm{~g} / \mathrm{l}$ of MSG and $50 \mathrm{~g} / \mathrm{l}$ of glucose and then incubated at $37^{\circ} \mathrm{C}$ for $72 \mathrm{~h}$. After the WCR, the reaction mixture was boiled at $80^{\circ} \mathrm{C}$ for $15 \mathrm{~min}$ to discontinue the GABA producing activity. The obtained reaction mixture of WCR was centrifuged and the obtained supernatant was directly used for analyzing extracellular GABA. The resultant yeast cells were re-washed and suspended in sterile distilled water. The yeast suspension was lysed by bead beating (Precellys24, Bertin Technologies, France), at six times with 5,000 rpm for $20 \mathrm{~s}$ each time, in the presence of $0.5 \mathrm{~mm}$ Zirconia/silica beads (Biospec, USA). Lysed yeast suspension was centrifuged, and the supernatant fluid was obtained for analyzing intracellular GABA. The obtained intra- and extracellular supernatant fluids were filtered through the $0.45 \mu \mathrm{m}$ cellulose membrane, 
before analysis of GABA.

\section{Identification by biochemical analysis}

For biochemical analysis of yeast-like strains, the API 20C AUX kit (BioMerieux, USA) was used according to the manufacturer's instructions in order to assist with identification. The obtained results were interpreted by using the database (version 4.0) in the Apiweb (www.apiweb.biomerieux.com) software.

\section{Identification by sequence analysis of 26S rDNA and IGS}

Identification of the isolates was performed by sequence analysis of $26 \mathrm{~S}$ rDNA region and intergenic spacer (IGS) regions. Colony PCR was conducted by using Taq DNA polymerase kit (GeneAll, Korea) obtained with crude templates, $25 \mathrm{pM}$ of universal primer sets: $26 \mathrm{~S}$ rDNA (NL1: 5'-GCATATCAATAAGCGGAGGAAAAG-3' and NL4: 5'-GGTCCGTGTTTCAAGACGG-3') and IGS (CNL12: 5'-CTGAACGCCTCTAAGTCAG-3' and CNS1: 5'-GAGACAAGCATATGACTACTG-3'). Amplification of both regions are conducted in a PCR thermal cycler (BioRad, USA) under the following conditions: 26S rDNA regions $\left(35\right.$ cycles of $94^{\circ} \mathrm{C}$ for $1 \mathrm{~min}, 52^{\circ} \mathrm{C}$ for $45 \mathrm{~s}, 72^{\circ} \mathrm{C}$ for $1 \mathrm{~min}$ ) and IGS regions (35 cycles of $94^{\circ} \mathrm{C}$ for $40 \mathrm{~s}, 58^{\circ} \mathrm{C}$ for $90 \mathrm{~s}, 72^{\circ} \mathrm{C}$ for $2 \mathrm{~min}$ ). Each PCR product was separated by gel electrophoresis and the bands were visualized by using the ChemiDoc XRS Imaging System (Bio-Rad) after staining with ethidium bromide. The confirmed PCR product was directly sequenced on DNA analyzer (ABI PRISM 3700, Applied Biosynthesis, USA) and analyzed by using the BLAST program (http: //www.ncbi.nlm.nih.gov/BLAST/). The multiple alignments and constructions of phylogenetic trees used the neighbor joining method [30] and CLUSTER W computer program. The phylogenetic tree was evaluated by bootstrap analysis through 1,000 replications [31, 32].

\section{Analysis of GABA}

The qualitative analysis of GABA was determined by using the thin-layer chromatography (DC-Alufolien $20 \times$ $20 \mathrm{~cm}$ Kieselgel 60, Merck, Germany) after separation in a solvent mixture ( $N$-butanol:acetic acid:water $=5: 3: 2)$ with $0.4 \%$ of ninhydrin for detection. After development, the plate was being dried for color detections on the hot plate at $80^{\circ} \mathrm{C}$ for $5 \mathrm{~min}$. For the quantitative analysis of GABA, a high performance liquid chromatography
(Waters Co., USA) equipped with a reversed-phase Primesep 100 (4.6 ×50 mm, SIELC Technologies, USA) and evaporative light scattering detector (Alltech, USA) was used as quantitative analysis of GABA by using $10 \%$ of acetonitrile in water containing $0.1 \%$ of trifluoroacetic acid as the mobile phase. Analysis was performed at $37^{\circ} \mathrm{C}$ with the isocratic flow rate of $1 \mathrm{ml} / \mathrm{min}$. Before injection, all samples were filtered by the $0.45 \mu \mathrm{m}$ membrane filter. The GABA production yield was also determined by measuring the total sum of intra- and extracellular GABA after WCR.

\section{Optimization of whole-cell reaction for GABA production}

For optimization of WCR, GABA production by selected yeasts was carried out. Unless otherwise stated, all reactions were performed in reactive solutions containing $20 \%$ of cells, $50 \mathrm{~g} / \mathrm{l}$ of glucose and $10 \mathrm{~g} / \mathrm{l}$ of MSG as substrates for WCR at $37^{\circ} \mathrm{C}$ in a $20 \mathrm{ml}$ test tube for $72 \mathrm{~h}$. To find the effects of carbon source in the WCR for GABA, different carbon sources of maltose, sucrose, xylose, mannose and mannitol were investigated with $10 \mathrm{~g} / \mathrm{l}$ of MSG. The effects of glucose addition were examined with concentrations of $0,10,30,50$ and $75 \mathrm{~g} / \mathrm{l}$ under the same condition. Optimal concentrations of MSG and cell concentrations for maximum GABA production by WCR varied from 0 to $30 \mathrm{~g} / \mathrm{l}$ and from 0 to $100 \%$, respectively. In addition, the effects of temperature for GABA production were measured at $29,37,50$ and $60^{\circ} \mathrm{C}$, and the effects of temperature stability on yeast cells before the WCR was also examined at $-20^{\circ} \mathrm{C}$ and $4{ }^{\circ} \mathrm{C}$. To determine the optimal concentration of PLP added to WCR for maximum GABA production, the WCR was performed at the presence of 1 or $2 \mathrm{mM}$ PLP or in the absence of PLP.

\section{Preparation of the yeast extract with GABA}

The selected yeast was inoculated in $10 \mathrm{ml}$ YM broth and cultivated at $29^{\circ} \mathrm{C}$ for $48 \mathrm{~h}$ at $600 \mathrm{rpm}$. Yeast culture was transferred in $250 \mathrm{ml}$ of YM broth and total $1 \mathrm{~L}$ of media was cultivated. Subsequently, cells were spun down at $4{ }^{\circ} \mathrm{C}, 5,000 \times \mathrm{g}$ for $15 \mathrm{~min}$, and the cell pellet was washed three times with distilled water. The WCR was performed as described above. After WCR, reacted solution was concentrated at $100^{\circ} \mathrm{C}$ for 20 min with stirring every $5 \mathrm{~min}$ and centrifuged at $4{ }^{\circ} \mathrm{C}, 5,000 \times g$ for $15 \mathrm{~min}$. The resulting supernatants were stored at $4{ }^{\circ} \mathrm{C}$ until fur- 
ther analysis.

\section{Amino acid composition of the yeast extract with GABA}

Yeast extract containing GABA was analyzed by LCMS-MS. For amino acid analysis with LC-MS analysis, $5 \mu \mathrm{l}$ aliquots were injected on an UPLC system (Acquity Ultra Performance LC, Xevo TQ-S (QQQ), Waters). The LC-MS-MS was controlled by MassLynx software (version 4.1). The UPLC column was a IMTAKA Intrada Amino Acid $(2 \times 5 \mathrm{~mm}, 3 \mathrm{um})$. The mobile phase was acetonitrile: $100 \mathrm{mM}$ ammonium formate $=20: 80(\mathrm{v} / \mathrm{v})$ (buffer A) and acetonitrile:THF:25 mM ammonium formate:formic acid $=$ 9:75:16:0.3 (v/v/v/v) (buffer B, $\mathrm{pH}$ 8.0). The flow rate was $0.4 \mathrm{ml} / \mathrm{min}$ and make gradient from $0 \%$ to $100 \%$ buffer A for $10 \mathrm{~min}$. The MS was equipped with an ESI interface operating at an ionization voltage of $+3000 \mathrm{~V}$ and a source temperature of $380^{\circ} \mathrm{C}$. The capillary voltage, con voltage and source offset were set at $3 \mathrm{kV}, 30 \mathrm{kV}$ and $30 \mathrm{~V}$ respectively. Quantification was performed using multiple reaction monitoring (MRM) [33]. The gas flow of desolvation, cone and nebulizer were set at $650 \mathrm{l} / \mathrm{Hr}, 150 \mathrm{l} / \mathrm{Hr}$ and 7 bar, respectively. For GABA analysis, Agilent 6410B Triple Quadrupole LC/MS (Agilent Technologies, Wilmington, USA) equipped with an ESI source was employed for the analysis. Glutamic acid and $\gamma$-amino butyric acid were purchased from Sigma Aldrich and used as reference standard. The $5 \mu$ l of the processed samples were injected into the HPLC system (1200 Series LC, Agilent Technologies, USA) fitted with Phenomenex Synergi Hydro-RP column $(4 \mu \mathrm{m}, 80 \AA$, $150 \times 2$ $\mathrm{mm}$ ), maintained at $30^{\circ} \mathrm{C}$. A mobile phase composed of $0.1 \%$ formic acid in distilled water (buffer A) and $0.1 \%$ formic acid in acetonitrile (buffer B) was used to separate the analysts and pumped into the ESI chamber at a flow rate of $0.5 \mathrm{ml} / \mathrm{min}$ for $20 \mathrm{~min}$. Fragmentor voltage and collision voltage was set at $70 \mathrm{~V}$. Detection of the ions was carried out in the MRM, by monitoring the transition pairs of $\mathrm{m} / \mathrm{z} 147.9 \rightarrow 83.9$ (glutamic acid), $646.2 \rightarrow 586.0$ and $104 \rightarrow 87$ ( $\gamma$-amino butyric acid). Data acquisition was performed with the MassHunter Software (Version B.04.00).

\section{Statistical analysis}

Data are expressed as the means values \pm S.D. $(n=3)$. The statistical significance was determined by one-way analysis of variance (ANOVA) when using the IBM SPSS software version 21 (IBM SPSS Inc. USA), followed by ANOVA with the Duncan's test. Differences with $p<0.05$ were considered statistically significant.

\section{Results and Discussion}

\section{Screening of yeast-like strains for GABA production from meju}

From a total of 643 yeast-like strains isolated from traditional fermented soybeans, meju, 103 strains displayed GABA producing activities by WCR while using the MSG as substrates. Then, ten GABA producing yeast-like strains, JBCC409, 440, 540, 541, 544, 555, $564,578,585$, and 588 were firstly selected as high GABA producing strains, which showed GABA productivity (Fig. 1). The extracellular GABA showed all examined yeast-like strains, but only three yeast-like strains of JBCC541, 564 and 585 produced extracellular GABA. In comparison, other yeast-like strains of JBCC409, 440, 540, 544, 555, 578 and 588 showed various different ratios of the intra- and extracellular GABA contents after the WCR as: JBCC409, 31:96; JBCC440, 38:62; JBCC540, 54:46; JBCC544, 65:35; JBCC555, 40:60; JBCC578, 15:85; and JBCC588, 17:83. The selected JBCC541 yeast-like strains were shown to synthesis the highest GABA of $4.8641 \mathrm{~g} / \mathrm{l}$ in extracellular GABA.

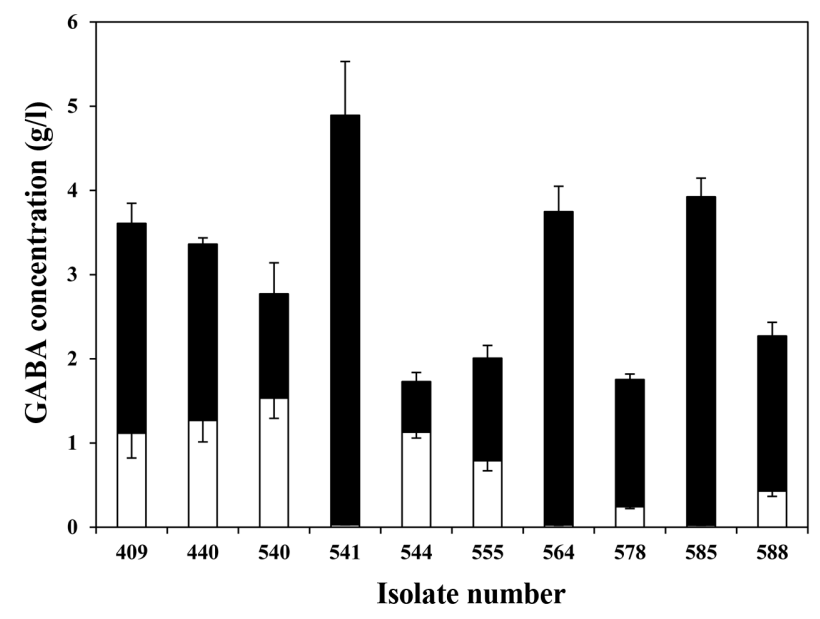

Fig. 1. Comparison of intracellular and extracellular $\gamma$ aminobutyric acid (GABA) content in $\mathbf{1 0}$ of screened yeast. Production of GABA in screened yeasts at $20 \%$ cells was examined at $37^{\circ} \mathrm{C}$ for $72 \mathrm{~h}$ in conversion solution containing $1 \%$ monosodium glutamate and $5 \%$ glucose. Extracellular content ( $\square$ ), Intracellular content ( $\square$ ). 
When we examined conversion ratios from MSG as substrates to GABA as products of WCR, the selected yeastlike strain of JBCC541 showed relatively high GABA conversion ratio with $99 \%$ at the extracellular. This GABA conversion capacity of WCR under our unoptimized WCR condition was higher than those of from previously reported yeast strains such as Saccharomyces cerevisiae (62.2 mg/l), Candida spp. (720.89 mg/l), C. utilis NBRC 10707 (653 mg/l), Pichia spp. (914.5 mg/l) and P. anomala ATCC 8168 (795 mg/l) (Masuda et al., 2008). Thus, we selected JBCC541 for further studies in this study.

\section{Identification of high-level of GABA production yeast-like strains, JBCC541}

When we examined the selected high level GABA producing yeast like strain by biochemical characters using API 20C AUX, the yeast like strain JBCC541 identified as $C$. gilliermondii with relatively low score of above $84 \%$ matching score. However, when the $26 \mathrm{~S}$ rDNA sequences was examined, the selected JBCC541 strains showed high level identity of 99-100\% with Debaryomyces hansenii (formally known as C. famata) and closely related to the sequences of $D$. hansenii species based on the evolutionary distance. Due to the low reliability, confused and inconsistency on the $26 \mathrm{~S}$ rDNA sequences for identification of yeasts even though high similarity, we examined IGS of the selected JBCC541 and compared with other type strains. Since IGS recently has been employed for clear resolutions of confused and inconsistence identification results for yeast strains according to the diversity of length polymorphisms, and show successful identifications results of closely related yeast species [34]. The IGS sequences of JBCC541 were about

Table 1. Identities of the IGS regions of Debaryomyces hansenii (Candida famata) JBCC541 with closest known D. hansenii ( $C$. famata) strains in the database.

\begin{tabular}{ccccc}
\hline Order & Database number* & Score & Identities (\%) & Gaps \\
\hline 1 & CBS 1961 & 508 & $382 / 431(89)$ & $18 / 431$ \\
2 & CLIB 660 & 580 & $383 / 415(92)$ & $10 / 415$ \\
3 & CBS 766 & 601 & $384 / 412(93)$ & $5 / 412$ \\
4 & CBS 1795T & 1572 & $880 / 894(98)$ & $1 / 894$ \\
5 & CLIB 622 & 1572 & $880 / 894(98)$ & $1 / 894$ \\
\hline
\end{tabular}

*Database number the DDBJ/EMBL/GenBank database by Basic Local Alignment Search Tool (BLAST).
2,800 bp and showed $89-98 \%$ identity with $D$. hansenii, as indicated in Table 1. However, no matches were found with the type strains of $C$. gilliermondii. This results strongly suggested that the selected JBCC541 strain must belong to $D$. hansenii, naming $D$. hansenii JBCC541 for further study (KACC 93182P).

\section{Optimal condition of whole-cell reactions for GABA con- versions by $D$. hansenii JBCC541}

To analyze the effects of carbon source on WCR, various carbon sources were used. The highest yield of GABA conversions was observed at glucose, showing about 2-folds of increased GABA production (Fig. 2A). It well agreed that, glucose was the appropriate carbon source addition for the GABA conversion among 10 types of carbon sources examined [35]. When we examined the optimal glucose concentrations ranging from 0-100 g/l, the GABA contents significantly increased to $10 \mathrm{~g} / \mathrm{l}$ of glucose concentration (Fig. 2B). No significant differences were observed at above $10 \mathrm{~g} / \mathrm{l}$ of glucose concentration on WCR. Previously, it has been reported that glucose addition could enhance the glutamate decarboxylase activity for WCR, and that GABA could not be produced without glucose addition even with glutamic acids as substrates due to unphosphorylated vitamin B6 in the absence of glucose [17]. However, we observed the GABA synthesis by WCR without glucose additions. This result could be caused by accumulation of glucose into yeast cell when culture in broth or according to different GAD activities from our isolated strain, JBCC541. To investigate the effects of different substrate concentrations on the conversion of GABA, different MSG concentrations with $10 \mathrm{~g} / \mathrm{l}$ of glucose was examined. Additions of MSG to the whole-cell reactive solutions resulted in an increase of GABA production at a concentration dependent manner to $10 \mathrm{~g} / \mathrm{l}$ of addition (Fig. 2C). Such result is in good agreement with GABA synthesis which is tended to decrease in yeast when the glutamic acids exceed by $20-50 \mathrm{~g} / \mathrm{l}$, due to strong regulations of GAD activities [35]. GAD catalyzes the irreversible a-decarboxylation of L-glutamate which produces GABA with PLP as the cofactor. As shown in Fig. 2D, the addition of PLP to WCR for GABA production significantly increases the GABA production yield at $1 \mathrm{mM}$. Previously, extracellular GABA contents were measured by $L$. paracasei NFRI 7415 in MRS medium which con- 

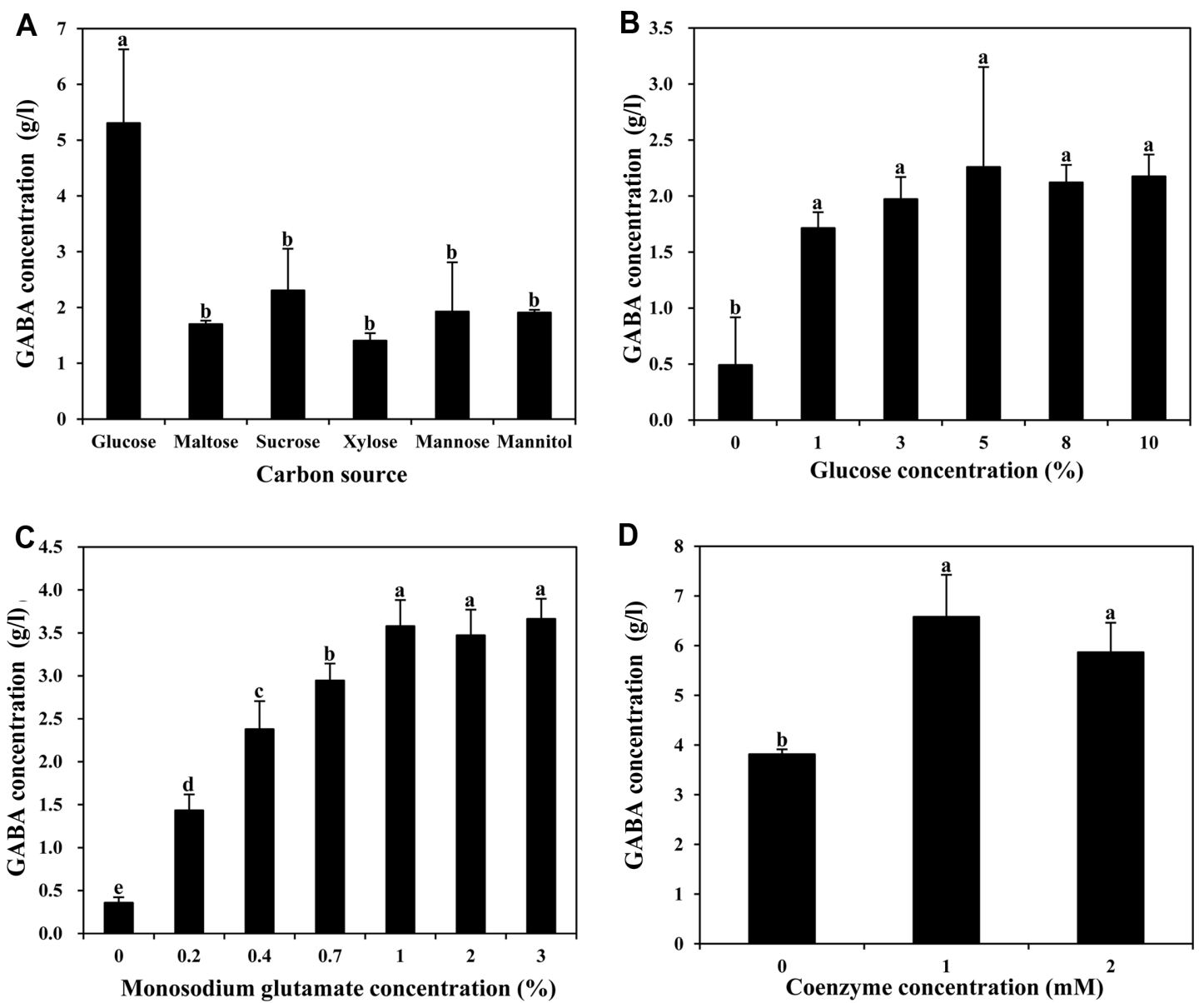

Fig. 2. Effect of different reactive solutions on extracellular GABA production by $D$. hansenii JBCC541. Type of carbon with $1 \%$ MSG concentration (A), glucose concentration with 1\% MSG concentration (B), MSG concentration with $5 \%$ concentration (C), and PLP concentration with $1 \%$ MSG and $5 \%$ glucose concentration (D).

tains PLP at various concentrations, and showed that PLP additions effectively increases the extracellular GABA production [36]. The result is in good agreement with our results on the WCR when using JBCC541 cells. We also examined effects of cell concentration for WCR (Fig. 3A). The concentration of JBCC541 cells for the GABA production was also examined, and the optimal cell concentration was found to be $20 \%$ cell of JBCC541. The GABA concentration increased with increased cell concentrations and reached the highest GABA production at $20 \%$ cell concentration. However, cell loading of over $20 \%$ caused significant decreases of GABA production and it could be due to the cell lysis caused by endoglucanase or protease in yeast cells or by decreasing mass transfer rates of substrates into the cells [37]. The optimal reaction temperature of the WCR for GAD activity by JBCC541 cells was determined as $37^{\circ} \mathrm{C}$ (Fig. 3B), and the results indicated high efficient conversions of MSG to GABA. The GAD activity of JBCC541 could be due to the decreased resistances of mass transfer on the cell surfaces, which covers the effect of cells and thus allows the synthesis rate to increase visibly. We also compared the whole cells for temperature stability of GAD activity by storing overnight at $-20^{\circ} \mathrm{C}$ and $4{ }^{\circ} \mathrm{C}$, and the frozen stored cells had no effects on WCR (Fig. 3C). However, when the JBCC541 cells were stored at $4{ }^{\circ} \mathrm{C}$, the GABA production activity on WCR was lower than the unstored JBCC541 cells. It seemed that the cells at $4{ }^{\circ} \mathrm{C}$ may cause an increased rate of enzyme inactivation.

\section{Characterization of the yeast extract with GABA from $D$. hansenii JBCC541}

Yeast extract were prepared in the presence or absence of glutamic acid by D. hansenii JBCC541 and 

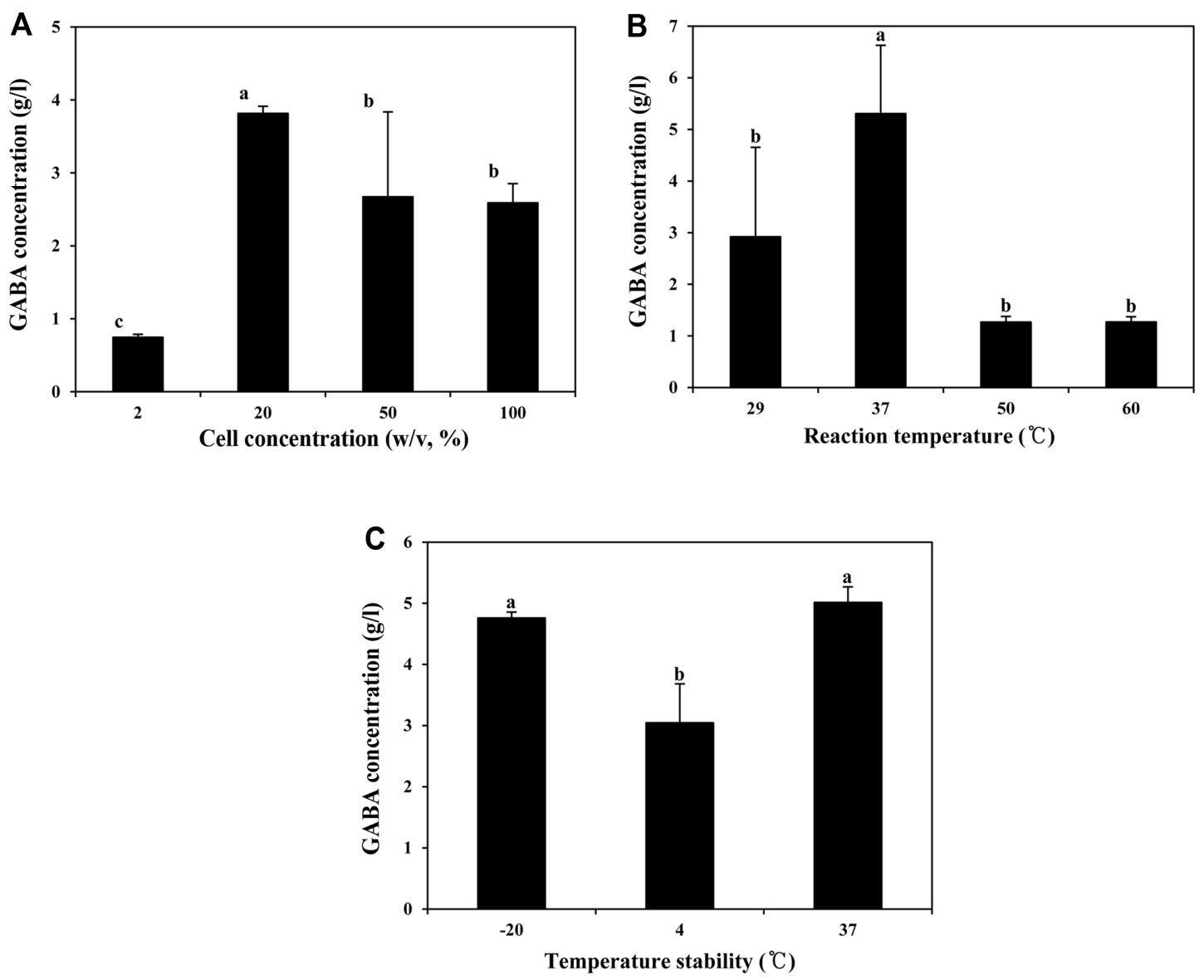

Fig. 3. Effect of different yeast concentration and temperature with reactive solutions on extracellular GABA production by D. hansenii JBCC541. Yeast cell concentration with 1\% MSG and 5\% glucose (A), reactive temperature with 1\% MSG and 5\% glucose concentration (B), temperature stability with $1 \%$ MSG and $5 \%$ glucose concentration (C).

the amino acid and GABA content were analyzed by GCMS or LC-MS-MS as described above. As shown in Table 2 , total amino acid content of the prepared yeast extract

Table 2. The amino acid composition of yeast extract by Debaryomyces hansenii JBCC541 after WCR and condensation process.

\begin{tabular}{lccccc}
\hline \multirow{2}{*}{ Amino acids } & \multicolumn{2}{c}{$\mathrm{mg} / \mathrm{l}$ extract } & & \multicolumn{2}{c}{$\mathrm{mg} / \mathrm{g}$ protein } \\
\cline { 2 - 3 } \cline { 5 - 6 } & Control $^{\mathrm{d}}$ & $\begin{array}{c}\text { Yeast } \\
\text { extract }\end{array}$ & & Control & $\begin{array}{c}\text { Yeast } \\
\text { extract }\end{array}$ \\
\hline Total amino acids $^{\mathrm{a}}$ & 2840.26 & 10733.86 & & 86.45 & 257.36 \\
Essential amino acids $^{\mathrm{b}}$ & 1385.86 & 1529.67 & & 42.18 & 36.68 \\
Flavour amino acids $^{\mathrm{c}}$ & 585.29 & 1519.43 & & 17.81 & 36.43 \\
\hline
\end{tabular}

${ }^{\text {aS }}$ um of 19 amino acids content as described in Fig. 4.

bValine, threonine, leucine, isoleucine, lysine, methionine, histidine, phenylalanine, and arginine.

'Glycine, alanine, aspartic acid, and glutamic acid.

dWhole cell reaction without monosodium glutamic acid. in the presence of glutamic acid as substrate was $10733.86 \mathrm{mg} / \mathrm{l}(257.36 \mathrm{mg} / \mathrm{g})$ which are approximately four times increased content than the yeast extract prepared in the absence of glutamic acid of $2840.26 \mathrm{mg} / \mathrm{l}$ (86.45 mg/g). Major amino acids profile was also changed depending on the addition of glutamic acid. Compared to the amino acids profile of yeast extract prepared without glutamic acid, major amino acids of the amino acids profile of yeast extract prepared with glutamic acid were alanine, lysine, glutamine, leucine, and valine (Fig. 4). Without glutamic acid addition, GABA concentration was $530 \mathrm{mg} / \mathrm{l}(16.13 \mathrm{mg} / \mathrm{g})$ in the prepared yeast extract, however, this GABA content greatly enhanced up to $6790 \mathrm{mg} / \mathrm{l}(162.80 \mathrm{mg} / \mathrm{g})$ in the presence of glutamic acid, which approximately 10 times higher GABA production. Flavor amino acids (FAA) of the prepared yeast extract were also highly enhanced than the yeast extract pre- 


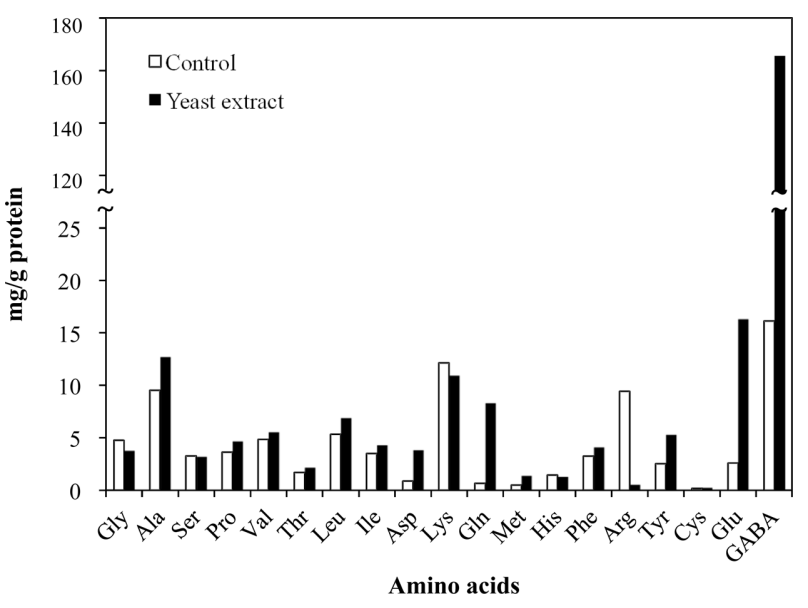

Fig. 4. The amino acid composition and GABA content of yeast extract by $D$. hansenii JBCC541 after whole cell reaction and condensation process.

pared without glutamic acid, indicating clearly that the prepared yeast extract might be useful for the preparation of the various functional foods by using this amino acids complex. Also, the essential amino acids such as valine, threonine, leucine, isoleucine, lysine, methionine, histidine, phenylalanine, and arginine account for about $40 \%$ of total amino acids. This amino acids composition is in good agreement with commercially available brewer's spent yeast extract which was prepared by mechanical disruption of cell wall [22].

The newly prepared yeast extract in this study by using novel non-Saccharomyces species, D. hansenii JBCC541, which isolated Korean traditional fermented foods showed very high content of GABA with other important amino acids with very simple process. This approach might be effective to obtain condensed yeast extract containing high-level GABA with valuable amino acid and could be a good source of application in food and dietary supplement industries as a protein and functional GABA rich ingredient.

\section{Acknowledgments}

This research was supported by research funds of Jeonbuk National University in 2021.

\section{Conflict of Interest}

The authors have no financial conflicts of interest to declare.

\section{References}

1. Ueno H. 2000. Enzymatic and structural aspects on glutamate decarboxylase. J. Mol. Catal. B Enzym. 10: 67-79.

2. Manyam BV, Trembly RD. 1984. Free and conjugated GABA in human cerebrospinal fluid: effect of degenerative neurologic disease and isoniazid. Brain Res. 307: 217-223.

3. Mody I, De Koninck Y, Otis TS, Soltesz I. 1994. Bridging the cleft at GABA synapses in the brain. Trends Neurosci. 17: 517-525.

4. Wong T, Guin C, Bottiflieri T, Snead OC. 2003. Gaba, $\gamma$-hydroxybutyric acid, and neurological disease. Ann. Neurol. 54: S3-S12.

5. Jakobs C, Jaeken J, Gibson KM. 1993. Inherited disorders of GABA metabolism. J. Inherit. Metab. Dis. 16: 704-715.

6. Hayakawa K, Kimura M, Kasaha K, Matsumoto K, Sansawa H, Yamori Y. 2004. Effect of a $\gamma$-aminobutyric acid-enriched dairy product on the blood pressure of spontaneously hypertensive and normotensive Wistar-Kyoto rats. Br. J. Nutr. 92: 411-417.

7. Nomura M, Kimoto H, Someya Y, Furukawa S, Suzuki I. 1998. Production of gamma-aminobutyric acid by cheese starters during cheese ripening. J. Dairy Sci. 81: 1486-1491.

8. Sawai Y, Yamaguchi Y, Miyama D, Yoshitomi H. 2001. Cycling treatment of anaerobic and aerobic incubation increases the content of $\gamma$-aminobutyric acid in tea shoots. Amino Acids 20 : 331-334.

9. Siragusa S, De Angelis M, Di Cagno R, Rizzello CG, Coda R, Gobbetti M. 2007. Synthesis of $\gamma$-aminobutyric acid by lactic acid bacteria isolated from a variety of Italian cheeses. Appl. Environ. Microbiol. 73: 7283-7290.

10. Nomura M, Kobayashi M, Ohmomo S, Okamoto T. 2000. Inactivation of the glutamate decarboxylase gene in Lactococcus lactis subsp. cremoris. Appl. Environ. Microbiol. 66: 2235-2237.

11. Su YC, Wang JJ, Lin TT, Pan TM. 2003. Production of the secondary metabolites $\gamma$-aminobutyric acid and monacolin K by Monascus. J. Ind. Microbiol. Biotechnol. 30: 41-46.

12. Dhakal R, Bajpai VK, Baek KH. 2012. Production of GABA ( $\gamma$-aminobutyric acid) by microorganisms: a review. Braz. J. Microbiol. 43: 1230-1241.

13. Li H, Cao Y. 2010. Lactic acid bacterial cell factories for $\gamma$-aminobutyric acid. Amino Acids 39: 1107-1116.

14. Huang J, Mei LH, Wu H, Lin DQ. 2007. Biosynthesis of $\gamma$-aminobutyric acid (GABA) using immobilized whole cells of Lactobacillus brevis. World J. Microbiol. Biotechnol. 23: 865-871.

15. Lee BJ, Kim JS, Kang YM, Lim JH, Kim YM, Lee MS, et al. 2010. Antioxidant activity and $\gamma$-aminobutyric acid (GABA) content in sea tangle fermented by Lactobacillus brevis $\mathrm{BJ} 20$ isolated from traditional fermented foods. Food Chem. 122: 271-276.

16. Jiang D, Cai Q, Gao A, Li J, Yang Y, Xu X, et al. 2013. Cloning and expression of a full-length glutamate decarboxylase gene from a high-yielding $\gamma$-aminobutyric acid yeast strain MJ2. Ann. Microbiol. 63: 487-494.

17. Masuda K, Guo XF, Uryu N, Hagiwara T, Watabe S. 2008. Isolation of marine yeasts collected from the Pacific Ocean showing a high production of $\gamma$-aminobutyric acid. Biosci. Biotechnol. Biochem. 
72: 3265-3272.

18. Lee JS, Lee SH, Kim JH, Yu JY. 1999. Isolation of wild killer yeast from traditional Meju and production of killer toxin. KSBB J. 14: 434-439.

19. Kim JH, Lee BH, Lee JS. 2002. Production of ribonucleotides by autolysis of Hansenula anomala grown on Korean ginseng steaming effluent. J. Biosci. Bioeng. 93: 318-321.

20. Kim JH, Lee DH, Lee JS. 2001. Production of galactooligosaccharide by $\beta$-galactosidase from Kluyveromyces maxianus var lactis OE-20. Biotechnol. Bioprocess Eng. 6: 337-340.

21. Spearman M, Chan S, Jung V, Kowbel V, Mendoza M, Miranda V, et al. 2016. Components of yeast (Saccharomyces cerevisiae) extract as defined media additives that support the growth and productivity of $\mathrm{CHO}$ cells. J. Biotechnol. 233: 129-142.

22. Vieira EF, Carvalho J, Pinto E, Cunha S, Almeida AA, Ferreira IM. 2016. Nutritive value, antioxidant activity and phenolic compounds profile of brewer's spent yeast extract. J. Food Comp. Anal. 52: 44-51.

23. Nagodawithana T. 1992. Yeast-derived flavours and flavour enhancers and their probable mode of action. Food Technol. 46: 138-144.

24. Schiffman SS. 1987. Recent developments in taste enhancement. Food Technol. 41: 72-73.

25. Akiyama S, Doi M, Arai Y, Nakao Y, Fukuda H. 1975. Production of yeast biomass. US Patent 3,909,532.

26. Révillion JPP, Pibernat CC, Ayub MAZ. 1996. Utilização de extratos de leveduras Saccharomyces cerevisiae na elaboração de vinhos espumantes. Ciência Tecnol. Alim. 16: 196-205.

27. de Carvalho CC. 2011. Enzymatic and whole cell catalysis: finding new strategies for old processes. Biotechnol. Adv. 29: 75-83.
28. Milner SE, Maguire AR. 2012. Recent trends in whole cell and isolated enzymes in enantioselective synthesis. ARKIVOC, 321-382.

29. Ishige T, Honda K, Shimizu S. 2005. Whole organism biocatalysis. Curr. Opin. Chem. Biol. 9: 174-180.

30. Saitou N, Nei M. 1987. The neighbor-joining method: a new method for reconstructing phylogenetic trees. Mol. Biol. Evol. 4: 406-425.

31. Kimura M. 1980. A simple method for estimating evolutionary rates of base substitutions through comparative studies of nucleotide sequences. J. Mol. Evol. 16: 111-120.

32. Felsenstein J. 1985. Confidence limits on phylogenies: an approach using the bootstrap. Evolution 39: 783-791.

33. Gu L, Jones AD, Last RL. 2007. LC-MS/MS assay for protein amino acids and metabolically related compounds for large-scale screening of metabolic phenotypes. Anal. Chem. 79: 8067-8075.

34. Quirós M, Martorell P, Valderrama MJ, Querol A, Peinado JM, de Silóniz MI. 2006. PCR-RFLP analysis of the IGS region of rDNA: a useful tool for the practical discrimination between species of the genus Debaryomyces. Antonie Van Leeuwenhoek 90: 211-219.

35. Kaku G, Hagiwara T. 2008. Method for producing $\gamma$-aminobutyric acid-containing food and yeast having high ability to produce $\gamma$ aminobutric acid. US Patent 20080138467.

36. Komatsuzaki N, Shima J, Kawamoto S, Momose H, Kimura T. 2005. Production of $\gamma$-aminobutyric acid (GABA) by Lactobacillus paracasei isolated from traditional fermented foods. Food Microbiol. 22: 497-504.

37. Scott JH, Schekman R. 1980. Lyticase: endoglucanase and protease activities that act together in yeast cell lysis. J. Bacteriol. 142: 414-423. 